\title{
Anti-EGFR/PBD Antibody-drug Conjugate ABBV-321
}

National Cancer Institute

\section{Source}

National Cancer Institute. Anti-EGFR/PBD Antibody-drug Conjugate ABBV-321. NCI

Thesaurus. Code C150590.

A antibody drug conjug ate (ADC) consisting of ABT-806 AM1, an affinity-matured humanized monoclonal antibody directed against the epidermal growth factor receptor (EGFR) conjug ated to a cytotoxic, DNA minor groove crosslinking agent and pyrrolobenzodiazepine (PBD) dimer, with potential antineoplastic activity. Upon intravenous administration of Anti-EGFR/PBD ADC ABBV-321, the monoclonal antibody moiety of ABBV-321 targets and binds to EGFR on tumor cell surfaces. Following receptor internalization and lysosome-mediated cleavage, the cytotoxic PBD moiety is released. In turn, the imine groups of the PBD moiety bind to the N2 positions of guanines on opposite strands of DNA. This induces DNA strand breaks, inhibits DNA replication, leads to G2/M cell cycle arrest, induces cell death, and inhibits the proliferation of EGFR-overexpressing tumor cells. EGFR, a receptor tyrosine kinase (RTK) that is overexpressed by a variety of cancers, plays a key role in tumor cell proliferation and survival. 